\title{
KADI BURHANEDDİN AHMED'İN KIZI KAYSERİ VALISİ VE SEFİRE HATİCE (MISIR) HATUN
}

(DULKADİR BEY'I NASIREDDIN MEHMED'İN EŞi)

\section{İlyas GÖKHAN*}

\section{Özet}

Türk ve İslam tarihinde devlet yönetiminde ve sosyal hayatta kadınların önemli rol oynadıkları görülür. Bu kadınlardan biri de Kadı Burhaneddin Ahmed'in kızı olup Dulkadirlilerin Beyi Nasıreddin Mehmed'in eşi Hatice (Mısır) Hatundur. Memluk devletine esir düşen oğlu Feyyaz'1 kurtarmak için iki defa Mısır'a elçi olarak gönderilmiştir. Bundan dolayı Mısır Hatun adı verilmiştir. Bir arada kocası tarafından Kayseri Valiliği'ne atanmıştır.

Anahtar Kelimeler: Dulkadir, Hatice (Misır) Hatun, Kayseri, Memluk, Kadı Burhaneddin

\section{KADI BURHANEDDIN AHMED'S DAUGHTER GIRLS KAYSERI GOVERNOR AND SEFİRE HATICE HATUN (EGYPT)}

\section{(THE RULER OF DULKADİR NASIREDDİN MEHMED'S WIFE)}

\begin{abstract}
In Turkish and Islamic history, women play an important role in state administration and social life. One of these women is the daughter of Kadi Burhaneddin Ahmed, Khadija (Misir) Hatun, the wife of Nasireddin Mehmed, the ruler of the Dulkadiris. He was sent twice as an envoy to Egypt to save his son Feyyaz, who was captured by the Mameluke state. Therefore, it was named as Egyptian Hatun. He was appointed as the Governor of Kayseri by his husband.
\end{abstract}

Key Words: Dulkadir, Hatice (Egypt) Hatun,Kayseri, Mameluke,Kadi Burhaneddin

Kadı Burhaneddin Ahmed, Eretna Devleti'nin Kayseri kadısı olup 1381 yılında bu devlete son vererek kendisini sultan ilan etti. 13. Yüzyllda Harizm bölgesinden göç ederek Kastamonu'ya yerleşen ailesinin Oğuzların Salur boyundan olduğu bilinir. Kendisi ve babası da dâhil ataları hep kadılık görevinde bulunurlar. ${ }^{1}$ Anadili Türkçenin yanında Arapça ve Farsça bilen Kadı Burhaneddin'in şiirlerinin toplandığı bir de divanı bulunmaktadır. Babasıyla birlikte Dımaşk ve Kahire'ye giden Kadı Burhaneddin aynı zamanda iyi bir askeri eğitim almıştır. 1364'te Kayseri'ye dönmüş ve Eretna Mehmed Bey tarafından kadılığa yükseltilmiş ve onun kızıyla evlenmiştir. Kadı Burhaneddin'in annesinin soyu da Selçuklu hanedanına dayanır. Kadı Burhaneddin kadılığın yanında askeri işlerle de uğraştı ve Kayseri'yi ele geçiren Karamanoğullarını buradan çıkardı. 1378'de Eretna hükümdarı Alâeddin Ali'nin vezirliğine getirildi. 1380'de Alaeddin Ali'nin ölümüyle yerine geçen küçük yaştaki oğlu II. Mehmed'i 1381'de tahtan uzaklaştıran Kadı Burhaneddin, kendini hükümdar ilan etti. Kadı Burhaneddin'in Alaeddin Ali (Zeynelabidin), Mehmed, Selçuk Hatun (Habibe) ve Hatice Hatun adlarında dört çocuğu vardı.

Âlim bir hükümdar olan Kadı Burhaneddin çocuklarının ciddi bir eğitim almasını sağladı. 1381-1398 tarihleri arasında Sivas ve Kayseri'de hüküm süren Kadı Burhaneddin Ahmed'in

\footnotetext{
* Prof Dr. Niğde Ömer Halisdemir Ünversitesi, Fen Edebiyat Fakültesi, Tarih Bölümü.

${ }^{1}$ Mirza Bala, Kadı Burhaneddin, İA, C. 6, İstanbul 1977 s. 46; Abdülkerim Özaydın, Kadı Burhaneddin, DİA, C.24, İstanbul 2001, s.74.
} 
ISSN-2199-353X

Online only at http://www.cahij.com/

hanımlarından biri komşu Dulkadir beyi Sevli'nin (Suli) kızıdır. Kendi kızı Hatice Hatunu da Sevli Bey'in yeğeni Nasıreddin Mehmet Bey'e vermiştir. ${ }^{2}$ Böylece iki devlet arasında akrabalık tesis edildi. Kadı Burhaneddin yaşadığı sürece Dulkadirlilerle dostane münasebetler sürdürdü. 1398'de Kadı Burhaneddin, Akkoyunlu emiri Karayülük Osman tarafından öldürülünce, onun memleketi olan Kayseri, Sivas ve Amasya gibi şehirler Osmanlı Sultanı Yıldırım Bayezid'in eline geçti. Kadı Burhaneddin'in oğlu Alâeddin Ali Bey (Zeynelabidin) ise zor durumda kalarak eniştesi Dulkadirli Nasıreddin Mehmed'e sığınmıştır. ${ }^{3}$ Sevli Bey ölünce yerine oğlu Sadaka geçtiyse de yeğeni, Kadı Burhaneddin'in damadı Nasıreddin Mehmed beyliği onun elinden alır. ${ }^{4}$

1399-1442 y1lları arasında Dulkadir beyi olan Nasıreddin Mehmed'in karıs1 Hatice Hatun onun yardımcılarından biriydi. Güçlü ve dirayetli bir hükümdar olan Kadı Burhaneddin Türk ve İslam devletleri arasında büyük bir itibar sahibiydi. Onun Timur'a dahi kafa tuttuğu bilinir. Hatta Timur ondan çekinmekteydi. Timur, ancak Kadı Burhaneddin'in öldürülmesinden sonra Anadolu'ya gelebilmişti. Babasının şöhreti Anadolu, Suriye ve Mısır'da yayılan Hatice Hatun da itibar sahibi bir kadındı. Hatice Hatun, kocasının uzun beylik döneminde siyasi olaylara karıştı. Nasıreddin Mehmed onu Kayseri valiliğine atadığ gibi iki defa da Mısır'a elçi olarak gönderdi. Hatice Hatun elçilik görevleri sırasında Memluk sultanları Şeyh Müeyyed Mahmud (1411-1421) ve Sultan Barsbay'la (1422-1438) görüşmeler yaptı. Onlardan büyük itibar gördü.

1402 Ankara Savaşı neticesinde Osmanlılar yenilince, Kayseri Timur tarafindan Karamanoğlu II. Mehmed Bey'e verilmişti. ${ }^{5}$ Bundan sonraki süreçte Karamanoğulları ile Dulkadirliler arasında Kayseri hâkimiyeti yüzünden uzun yıllar devam edecek bir mücadele süreci başladı. Kayseri'nin Dulkadirlilerin eline geçtiği tarih ihtilaflıdır. Kayseri İç Kalesinin doğu kapısının iç yüzünde bulunan ve Nasıreddin Mehmed'in oğlu Kayseri Valisi Emir Hüsami Hasan adına H. 814/M. 1411 yılına ait bir kitabe bulunur. ${ }^{6}$ Buna dayanarak bu tarihin Dulkadirlilerin şehre hâkim olduğunu kabul edebilir. Bir müddet sonra Kayseri yeniden Karamanoğullarının eline geçer. Bu da Karaman valisi Şeyh Çelebi ve oğlu Demir adına yazdırılan Kayseri Kalesinin Aslanlı kapısının batısındaki kitabeden anlaşılmaktadır. ${ }^{7}$ Bu kitabede Kayseri'nin Dulkadir Türkmenlerinden alındığını belirtmektedir.

Dulkadir beyi Nasıreddin Mehmed, Osmanlı Devleti'nin Fetret devrinde (1402-1413) Çelebi Mehmed'i destekleyerek kızı Emine Hatun'u ona vermişti. Dulkadirlilerin Osmanlılarla yakınlaşması öteden beri bu beyliği kendilerine bağlı olarak gören Memlukları endişelendirmişti. Memluk Sultanı Şeyh Müeyyed 1414'te Suriye'de kendisine karşı başlatılan isyanı önledikten sonra Dulkadirlilerin üzerine yürüyerek onların merkezi Elbistan'a girdi. Sultan, Darende ve Antep'i Dulkadirlilerden alarak Mısır'a döndü. ${ }^{8}$ Nasıreddin Mehmed bunun üzerine Memluk Sultanına isyan eden Şam Valisi Kanıbeg'e yardım etmek için oğullarından birini onun yanına gönderdi. Ancak Memluklar bu isyanı bastırdılar ve esir ettikleri Nasıreddin Mehmed'in adı bilinmeyen bir oğlunu da Kahire'ye götürüp

2 J. H. Mordtmann, Dulkadırlılar (İkmal eden M. H. Yinanç), İA, C. 4, İstanbul 1977, s.661.

${ }^{3}$ Mehmed Neşri, Kitâb-ı Cihan- Nümâ, C. I (Yay.: M. A. Köymen, F. R. Unat), TTK Yay., Ankara 1987, s.321; İsmail Hakkı Uzunçarşı1l, Anadolu Beylikleri, TTK Yay. Ankara 1983, s.167-168; J. H. Mordtmann, Eskişehir 1997, s.659.

${ }^{4}$ Yaşar Yücel, Kadı Burhaneddin Ahmed ve Devleti, Sevinç Matbaası, Ankara 1983, s.162; Refet Yinanç, Dulkadir Beyliği, TTK Yayınları Ankara 1989, s.34.

${ }^{5}$ Ahmet Nazif, Kayseri Tarihi, (Mirat-ı Kayseriyye), (Hazr. M. Palamutoğlu), Kayseri 1987, s.106-107; Halil Erkiletlioğlu, Kayseri Tarihi, İl Kültür Müdürlüğ̈̈ Yayınları, Kayseri 1993, s.219.

${ }^{6}$ Mehmet Çayırdağ, "Kayseri'de XIV. ve XV. Yüzyıllarda İki Emir Ailesi Emir Zahireddin Mahmud ve Emir Şeyh Çelebi." Vakıflar Dergisi, 27 (1998), s.141; Erkiletlioğlu, s.219.

${ }^{7}$ Erkiletlioğlu, s.219.

${ }^{8}$ R. Yinanç, s.41-42. 
ISSN-2199-353X

Online only at http://www.cahij.com/

hapsettiler. Bir yıldan fazla bir süre oğlundan haber alamayan Nasıreddin Mehmed büyük endişe duydu ve onu kurtarmak için hanımı Hatice Hatun'u, Elbistan'dan Mısır'a gönderdi. Uzun bir yolculuktan sonra 31 Ocak 1417'de Kahire'ye ulaşan Hatice Hatun'a Sultan Şeyh Müeyyed Mahmud iyi davranmış ve izzett-i ikramda bulunmuştur. Sultan, Hatice Hatun'un oğluyla buluşmasını sağlamıştır. Kahire'de Kalatü'l-Cebel'de (Kahire Kalesi) hapis edilen Dulkadir beyinin oğlu annesinin girişimi ile serbest bırakılmış ve Maraş'a dönmüştür. ${ }^{9}$ Bu olayı İbn Tagribirdî, Nasıreddin Mehmed ve oğlunun birlikte Sultanın yanına gittiklerini belirterek yanılmıştır. ${ }^{10}$ Hatice (Mısır) Hatun elçilik görevini başarı ile tamamlayarak memleketine dönmüştür.

Kayseri hâkimiyeti yüzünden Karamanoğulları ve Dulkadiroğulları rekabet halindeydi. Dulkadirliler Kayseri'yi Karamanoğullarından almışlardı. Karamanoğulları ise Kayseri’yi yeniden ele geçirmek amacıyla 1419'da bir saldırı başlatırlar. Karamanlıların bu seferine Ramazanoğluları da katıldılar. Karamanoğlu Mehmet Bey yanında oğlu Mustafa ve damadı Ramazanoğlu İbrahim olduğu halde Kayseri üzerine yürüdü. Dulkadiroğlu Nasıreddin Mehmed bu orduyu yendiği gibi Karaman beyini esir alıp oğlunu da öldürdü. Esir edilen Karamanoğlu Mehmet Bey Memluk sultanına gönderildi. 1420'de Memluk Sultanı Şeyh'in ölümü ile yerine Tatar (1421-1422) sultan olmuştu. Bu arada Dulkadirlilerden Tuğrak Bey, Malatya'yı Memluklardan almıştı. Nasıreddin Mehmed'in kardeşi Alâeddin Ali Bey ise Kahire'ye giderek Memluk sultanına itaat edince ona Maraş'ın yanı sıra Antep ve Darende'de verilmişti. 1422'de Memluk tahtına Barsbay çıkınca Antep ve Darende Nasıreddin Mehmed'e verildi. Nasıreddin Mehmed'den kaçarak Kahire'ye sığınan kardeşi Alâeddin Ali Bey'e Memluk sultanı itibar etmemiş ve o da Suriye'de karışıklıklar çıkarmaya çalışınca öldürülmüştü.

Nasıreddin Mehmed zamanında Dulkadirli-Akkoyunlu ilişkileri de gerginleşir. 1426'da Malatya'ya doğru sefere çıkan Akkoyunlu beyi Karayülük Osman Harput'u (Elazığ) ele geçirdi. Sultan Barsbay'ın yanında Akkoyunlulara karşı sefere çıkan Nasıreddin Mehmed'in de bulunduğu Memluk ordusu Diyarbakır kuşatmasında başarısız oldu. ${ }^{11}$ Bu arada Alâeddin Ali Bey'in oğlu Hamza Bey Memluklarla sıkı bir ilişkiye girerek Dulkadir ülkesinde hak iddia etmeye başladı. Memluklar ona destek vererek Maraş'1 aldılar ve burada bulunan Nasıreddin Mehmed'in oğlu Feyyaz esir edilerek Kahire'ye götürülüp zindana atıldı (1434). ${ }^{12}$

$\mathrm{Bu}$ firsattan istifade eden ve Memlukların desteğini alan Karamanoğulları da Kayseri'yi ele geçirir. Ancak Nasıreddin Mehmed eşi Hatice Hatun'u ikinci kez Mısır'a göndererek Kayseri'nin anahtarını Sultan Barsbay'a sunar. Memluklar da Kayseri'nin Dulkadirlilere verilmesini sağlarlar. Nasıreddin Mehmed, Kayseri'ye vali olarak eşi Hatice Hatun'u tayin eder. Yukarıda da izah ettiğimiz gibi Kayseri'nin Karamanoğulları tarafından işgali üzerine Nasıreddin Mehmed karısı Mısır Hatun'u Kahire'ye göndererek hem Memlukların elinde esir olan oğlu Feyyaz'1 kurtarmak ve hem de Kayseri'nin Dulkadirlilere verilmesi için girişimlerde bulunur. Bu amaçlarla uzun bir yolculuktan sonra Kahire'ye ulaşan Misır Hatun, Memluk sultanını Baybars'ı ikna etmiş ve Kayseri'nin Dulkadirlilere verilmesini sağlamıştır. Dönemin ünlü Memluk tarihçisi el-Makrîzî, bu olayı şöyle anlatmaktadır: "1 Şevval 838'de (M.30 Nisan 1435) Memluk ordusunun Halep'ten Kayseri'yi almak

\footnotetext{
${ }^{9}$ Makrîzî, Kitabü's-Sülük, C.IV/I, (Tahk.: Said Abdülfettah Aşur) Matbaatü Darül Kütüp, 1972, s.374; İbn Tagribirdî, Nücumüz-Zahire,(tahkik. Muhammed Şemseddin Hüseyin) C. 13, Kahire 1992, s.201-202.

${ }^{10}$ İbn Tagribirdî, s.201-202.

${ }^{11}$ Bu konuda ayrıntılı bilgi için bkz: İlyas Gökhan-Rıdvan Yiğit, Sultan Barsbay'ın Diyarbakır Seferi, Kapadokya Tarih ve Sosyal Bilimler Dergisi, Sayı 1, Aralık 2013, s.1-13.

${ }^{12}$ Mükrimin Halil Yinanç, Elbistan, İA, C. 4. Eskişehir 1997, s. 228; R. Yinanç, s.48; İlyas Gökhan, Dulkadir Beyliği, İslam Tarihi ve Medeniyeti C.11, Siyer Yayınları, İstanbul 2018, s.292.
} 
ISSN-2199-353X

Online only at http://www.cahij.com/

için hareket ettiğini ögrrenen Nasıreddin Mehmet Bey, Hanımı Hatice Hatun'u sultana göndererek Kayseri'nin anahtarların sundu. Hatice Hatun, Sultanın naibi ile görüşü̈. Onun oğlu Feyyaz Kahire kalesinde tutuklu bulunmaktaydr. Haleb'ten sultana mektup yazıldı. Bu kadın 17 Şevval'de (16 Mayls) Haleb'den (Kahire'ye)hareket etti. Hatice Hatun Şevval ayı içinde Kahire'ye ulaşt. Burada bir müddet ikamet etti. Kal'atü'l-Cebel'de hediyelerle karşılandl. Orada oğlunun serbest birakılmasını istedi. Sultan tarafindan nezaketle karşılanan Hatice Hatun'un bütün istekleri kabul edildi. Oğlu Feyyaz'a Maraş naipliği verildi. Karamanoğlu İbrahim Bey, Hatice Hatun'un Kahire'ye gittiği haberini alınca Memlukların yetkililerine Kayseri'nin durumunun ne olacağını sordu. O da Şevval ayının 28'de(27 Mayls) Halep'ten (Kahire'ye) hareket etti. Burada birçok mal vaat etti. ${ }^{13}$ Hatice Hatun'un Kayseri'yi istemek üzere Kahire'ye gittiği haberini alan Karamanoğlu İbrahim Bey de Memluk Sultanı ile görüşmek üzere Mısır'a doğru yola çıkmış ve Haleb'e gelerek Memluklara birçok vaatte bulunmuştu.

Hatice Hatun'un Kahire ziyaretine şahit olanlardan biri de Mısırlı muhaddis ve tarihçi İbn Hacer'dir. O da Hatice Hatun'un Kahire'ye geldiğini, oğlu için sultandan af dilediğini ve Kayseri'nin anahtarlarını sultana sunduğunu yazmaktadır. Müellif Hatice Hatun'un, Nasıreddin Mehmed Bey'in karıs1 ve Kayseri naibi olduğunu belirtir. ${ }^{14}$

Olayın şahitlerinden bir başka Memluk tarihçisi İbn Tagribirdi “ Dulkadiroğlu Halep ordusunun Kayseri’yi elinden almak için üzerine geldiğini öğrenince hemen hanımı Hatice'yi hediyelerle ve Kayseri şehrinin anahtarlarlyla birlikte sultana gönderdi. Bu hatun sultana kocasinin sultanin Kayseri'deki naibi olduğunu belirterek, bir süredir Kal'atü'l-Cebel'de (Kahire Kalesi) hapiste bulunan oğlu Feyyaz'ın serbest bırakılmasını talep edecekti. Dulkadiroğlu bunun için dahi para vaat etmişti. Bu Hatice Hatun Şevval ayının sonlarına doğru Mısır'a geldi, yanındaki hediyeleri takdim etti ve kocasının ricalarını iletti. Sultan hediyeleri kabul etti ve kadının oğlunu serbest bıraktıktan başka ona Maraş naibliğini verdi " ${ }^{\prime \prime} \mathrm{Bu}$ arada Dulkadiroğlu Nasıreddin Mehmed, Memluk Sultanına isyan eden Canibeg adlı komutanı desteklemekteydi. Bu haber Mısır'a gelmesine rağmen daha Kahire'den ayrılmamış olan Hatice Hatun ve oğlu Feyyaz'ın Maraş'a dönmesine engel olunmadı. Nasıreddin Mehmed'in diğer oğlu Süleyman annesi Hatice Hatun ve kardeşinin Kahire'den Dulkadir ülkesine doğru yola çıktığı haberini babasını bildirdi. ${ }^{16}$

Daha önce olduğu gibi Hatice Hatun bir kez daha elçilik görevini başarı ile tamamlayarak Maraş'a dönmüştür. Bu arada denge politikası takip eden Nasıreddin Mehmed, kızlarından Nefise Hatun'u isyan eden Memluk komutanı Canibeg'e verir. Canibeg Akkoyunlu Karayülük Osman Bey tarafından öldürülünce, Nasıreddin Mehmed'in dul kalan kızı Nefise Hatun'u Sultan Barsbay'a vermek ister. Ancak 1438'de Barsbay'ın ölümü üzerine Nefise Hatun Memlukların yeni sultanı olan Sultan Çakmak'a verilir. Kızını çeyizi ile birlikte Kahire'ye götüren Nasıreddin Mehmed 31 Aralık 1440 yılında buraya ulaşır. Kaynaklar belirtmese de muhtemelen Hatice Hatun'da kocasıyla birlikte kızının düğününe katılmak için Kahire'ye gelir. Dulkadir Beyi Kahire'ye varışından bir hafta sonra Sultan Çakmak'la kızı Nefise Hatun'un muhteşem bir düğünle evlendirdikten sonra merkezi

\footnotetext{
${ }^{13}$ Makrîzî, Kitabü’s-Sülük, C.IV/II, (Tahk: Said Abdülfettah Aşur) Matbaatü Dari’1 Kütüp, 1972,s.946-947.

${ }^{14}$ İbn Hacer, İnbâi'l-Gumr bi- Ebnâ'l- Umr, C.8, Darü-1- Kütibi'l- İlmiye, Beyrut 1986,s.339-340,

15 İbn Tagribirdi, Nücumü'z- Zahire,(çev. Ahsen Batur), Selenge Yayınları İstanbul 2013, s.487.

${ }^{16}$ İbn Tagribirdi, s.489.
} 
ISSN-2199-353X

Online only at http://www.cahij.com/

Elbistan'a dönmüştür. Sultan Çakmak, Nasıreddin Mehmed'e kızının çeyizine karşılık 30 bin dinar vermiştir. ${ }^{17}$

Hatice Hatun kocası tarafından Kayseri valiliğine tayin edilmiştir. Kayseri'de uzun yıllar yöneticilik yapmıştır. Başarılı sefirelik görevlerini iki defa Mısır Memluklarının başkenti Kahire'ye kadar giderek yapmış ve esaret altında olan iki oğlunu kurtardığ1 gibi Karamanoğullarına karşı Memlukların Dulkadiroğullarını desteklemesini sağlamıştır. Hatice Hatun'a Mısır'a yaptığı ziyaretler sonrası "Mısır Hatun" unvanı verilmiştir. Halil Edhem Bey, Dulkadir beyi Nasıreddin Mehmed'in karıs1 Mısır Hatun'un Kudüs'te Haram-1 Şerifin kuzey kenarında kendi adına tamir 836'da (M.1433) ettirdiği Gadiriye Medresesi'nin kitabesinde adının yazılı olduğunu ifade etmektedir. ${ }^{18}$ Nasıreddin Mehmed Bey, 1442'de vefat etmiştir. Hatice Hatun bir müddet daha yaşamıştır. Ne zaman vefat ettiği bilinmemektedir. Kaynaklarda belirtilmemekle birlikte Nasıreddin Mehmed'in ve eşin Mısır Hatun'un daha sağlığında oğlu Süleyman Bey tarafından 1440'da yaptırdığı, Pınarbaşı ilçesine bağlı Pazarören Nahiyesi'nin kuzeyindeki Köşker (Köşkerli) Dağı'nın eteğinde ve Melikgazi köyünün $6 \mathrm{~km}$ güneybatısında, Koçcağız denilen mevkide olan türbeye defnedildiği ileri sürülmektedir. Bu türbe 1454'de vefat eden Dulkadir Bey'i Süleyman'ın türbesi olarak bilinmektedir. Süleyman Bey de bu türbeye defnedilmiştir. Türbe iki katlı olup üstü mescit ve altı ise sandukaların bulunduğu kısımdır. ${ }^{19}$ Altı sanduka bulunan bu türbe definecilerin saldırısına uğrayıp sandukalar tahrip edilmiştir. Yakın zamanlarda bu türbe restore edilmiştir. Dulkadir Beyliğinde Mısır adının isim olarak verildiği görülmektedir. Hatice Hatun'ın oğlu Süleyman Bey'in kızlarından birinin adına annesinin adını vermiştir. Kayseri Pınarbaşı kazası Melikgazi mevkiinde bulunan Melik Gazi Türbesi’nin dış duvarlarında bulunan kitabe taşlarından birinde el-merhume Misır Hatun bint Süleyman Beg adı yazilıdır. $^{20}$

Kocası Nasıreddin Mehmet Bey'le birlikte ülkesini yöneten Misır Hatun adına Kayseri'de Hatuniye Medresesi inşa edilmişti. ${ }^{21} \mathrm{Bu}$ medresenin 1980'lerde onarımı sırasında temelleri altında eski bir İslami yapısının ortaya çıktı̆̆ görülmüştür. Muhtemelen Nasıreddin Mehmed Bey eski bir yapının üzerine bu medreseyi inşa ettirmiştir. 1411 ile 1435 arasında Kayseri'nin Dulkadiroğulları elinde kaldığ 1 ve süreçte inşa edilen medresenin Şamiler medresesi adıyla anıldığ tarihi üzerine çalışmaları ile bilinen Mehmet Çayırdağ Karamanoğulları dönemi tarihçisi Şikarî’nin

\footnotetext{
${ }^{17}$ Besim Atalay, Maraş Tarihi ve Coğrafyası, (Hazr. İ. Gökhan_M. Karataş), Kahramanmaraş 2008, s.78; Mordtmann, s.660; RYinanç, 1989, s.54-55; Gökhan, s.294.

${ }^{18}$ Halil Edhem Bey kendisine bu malumatı müsteşrik Vanberham'ın verdiğini ve kitabenin büyük bir kısmının bozulduğuna yazar. Bu bilginin Mucireddin'in Kudüs Tarihi olan El-Ünsü'l-Celil bi Tarihi'l-Kuds ve'l-Halil adlı eserinden alınmıştır. H.1283 baskısı s. 391. Bu eserdeki Arapça metnin tercümesi “ Kudüs'te Mescid-i Aksa dahilinde bulunan Medresetü'l-Gadiriye Emir Nasıreddin Mehmed'in vakfıdır. Ondan sonra eşi Mısır hatun tamir ettirmiştir.Medreseye ait bir vakfiye bulunmamaktadır. Ancak malının bir kısmını vakfettiğine dair bir yapmıştır. Bu tutană̆ın 897 yılına ait olduğu tespit edilmiştir. (Kütüphane-i Umumiyede 4899-22 numaralı yazma nüshada 877 yazılıdır.) El-Melikü'l- Eşref Barsbay'ın saltanatında Rebiyülahir sene 836'da inşa ettiler." Halil Edhem, Melik Gazi, Anadolu'da İslami Kitabeler, (TOEM), Beşinci Sene, Sayı 32, 1 Haziran 1331,s.456. ${ }^{19}$ Yıldıray Özbek-Celil Arslan, Kayseri Taşınmaz Varlıklar Envanteri, C. III, Kayseri 2008, s.1102.

${ }^{20}$ Halil Edhem, Melik Gazi, Anadolu'da İslami Kitabeler, (TOEM), Beşinci Sene, Sayı 32, 1 Haziran 1331, s.456.

${ }^{21}$ Hatuniye Medresesinin kitabesin; “Bu medreseyi, büyük emîr, hayır ve hasenet sahibi, Arap ve Acem ’in sultanlar sultanı, dünyada emirler sultanı dünya ve dinin yardımcısı saadetli Emîr Abdürreşid [Zeyneddin olacak] oğlu, Merhum Halil oğlu Mehmed -Allah iktidar günlerini dâim etsin, Müslümanları da, o durdukça faydalandırsın sevâbını da umarak, ilim öğrenmekle uğraşacak bilgin ve öğrenciler için büyük Şevval 835 (Haziran 1432) de yağptırdl. Allah ondan lütüf ve ihsanıyla kabul buyursun” Bkz: Kemal Göde, Halil Edhem (Eldem) Kayseri Şehri Selçuklu Tarihinden Bir Bölüm, Kayseri Büyükşehir Belediyesi Yayınları Kayseri 2011, s.. 104-105
} 
ISSN-2199-353X

Online only at http://www.cahij.com/

Dulkadirlileri "Şamiler" şeklinde ifade etttiğini belirtmektedir. Ona göre Dulkadir beyliği Maraş ve Elbistan'dan Şam'ın kuzeyine yani Halep'e kadar olan yerleri zaman zaman idare etmekteydiler. Bundan dolayı Şamiler adıyla anılmışlardır. ${ }^{22}$ Ancak Dulkadirlilerin Şam ve Mısır'a hâkim olan Memluklara da tabi oldukları unutulmamalıdır. Şikari tarihinde ayrıca birkaç yerde açıkça "Şamiler" ifadesinin Memluklar için kullanıldığı görülmektedir. ${ }^{23}$ Şamiler Medresesi ifadesi, Dulkadirlilerin Memluklara bağlı olmasından kaynaklanmaktadır. Refet Yinanç bu medreseyi Nasırıyye Medresesi olarak ifade etmektedir. ${ }^{24}$

\section{SONUÇ}

14. Yüzyılın sonlarında Kayseri ve Sivas'a hâkim olan Kadı Burhaneddin Ahmed ile Elbistan ve Maraş’ta kurulmuş olan Dulkadir Beyliği arasında siyasi ilişkiler neticesinde karşılıklı kız alıp verilmişti. $\mathrm{Bu}$ tür evlilikler beylikler ya da devletler arasında görülen siyasi akrabalıklardı. Bir başkasına karşı iki taraf arasında akrabalık sonucunda ittifak yapılmaktaydı. Kadı Burhaneddin'in kızı Hatice Hatun, Dulkadir Beyi Halil oğlu Nasıreddin Mehmed'le evlendirilmişti. Buna karşıllı Kadı Burhaneddin de Nasıreddin Mehmed'in amcası Sevli Bey'in kızı ile evlenmişti. Uzun yıllar Dulkadir Beyliğini yöneten Nasıreddin Mehmed idari işlerde eşi Hatice Hatun'a da görev vermişti. Kadı Burhaneddin gibi meşhur bir kişinin kızı olması sebebiyle Hatice Hatun'a komşu devlet ve beyliklerin yöneticileri saygı duymuşlardı. Bunu bilen Nasıreddin Mehmed, eşine Kayseri naipliğini vermişti. Bunun yanında sık sık ilişkilerinin bozulduğu, oğullarını esir eden ve saldırılarına maruz kaldığı Memluk sultanlarına Hatice Hatun'u elçi olarak göndermişti. Hatice Hatun da bu görevleri başarı ile yapmış ve sık sık Mısır'a gittiği için kendisine "Mısır Hatun" adı verilmişti. Bu makalede açıkladığımız bilgiler ışığında Hatice Hatun'un Türk tarihinde görülen ilk kadın elçi (sefire) olduğunu söyleyebiliriz. Hatice Hatun adına Kayseri'de kocası tarafından yaptırılan ve Hatuniye (Şamiye) Medresesi, yüzyıllardır ayakta duran bir yapıdır.

\footnotetext{
${ }^{22}$ Mehmet Çayırdağ, Kayseri'de Selçuklu ve Beylikler Dönemine Ait Bazı Kitabe ve Mezar Taşları, Tarih Dergisi, Say1 34, s.1984, s.517-518:

${ }^{23}$ Şikarî, Karamanname (Zamanın kahramanı Karamanîler’in tarihi) Hazr: Metin Sözen, Necdet Sakaoğlu), Karaman Valiliğ-Karaman Belediyesi, İstanbul 2005, s.199-202.

${ }^{24}$ Refet Yinanç, s. 130.
} 
ISSN-2199-353X

Online only at http://www.cahij.com/

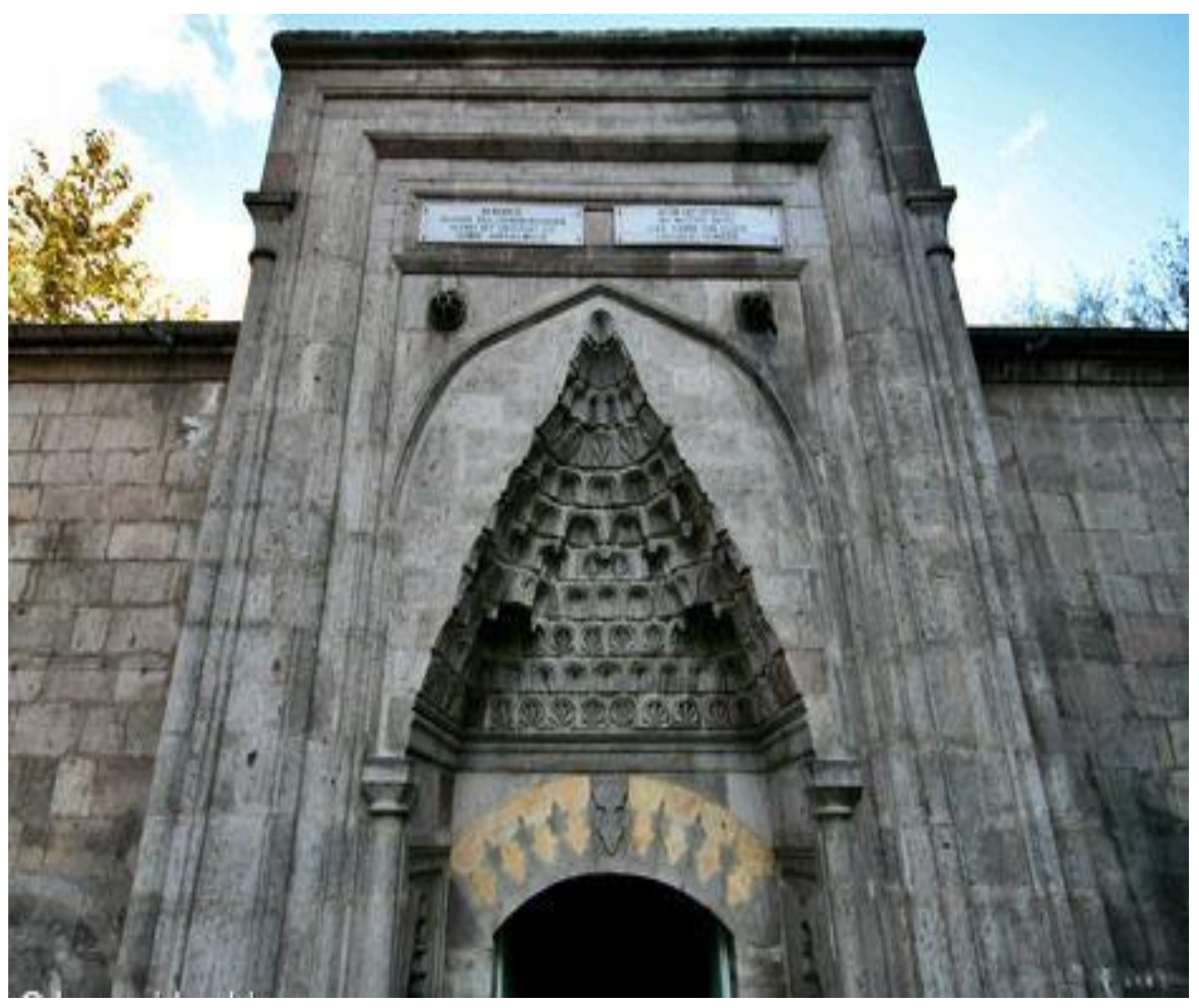

Hatice Hatun adına yaptırılan Hatuniye Medresesi ${ }^{25}$

${ }^{25}$ http://kayseriden.biz/icerik.asp?ICID=209; http://www.kayseri.gov.tr/diger-camii-ve-medreseler 


\section{ISSN-2199-353X}

Online only at http://www.cahij.com/

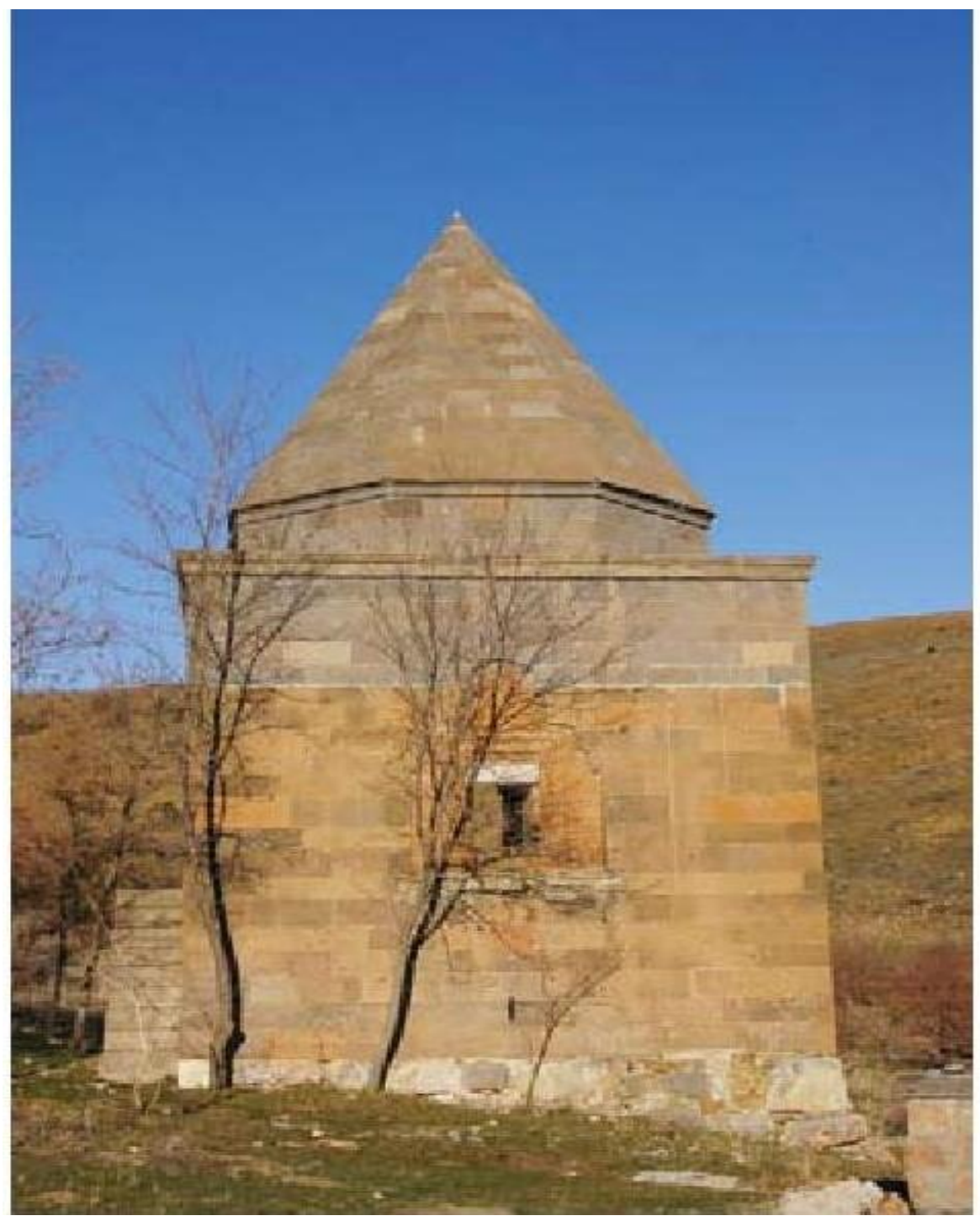

Dulkadiroğlu Süleyman Bey Türbesi ${ }^{26}$

${ }^{26}$ Özbek-Arslan, s. 1103. 


\section{KAYNAKLAR}

AHMET NAZİ, Kayseri Tarihi, (Mirat-1 Kayseriyye), (Hazr. M. Palamutoğlu), Kayseri 1987. ATALAY, Besim, Maraş Tarihi ve Coğrafyası, (Hazr. İ. Gökhan-M. Karataş), Kahramanmaraş 2008.

BALA, Mirza, Kadı Burhaneddin, İA, C. 6, İstanbul 1977.

ÇAYIRDAĞ, Mehmet. "Kayseri'de XIV. ve XV. Yüzyıllarda İki Emir Ailesi Emir Zahireddin Mahmud ve Emir Şeyh Çelebi." Vakıflar Dergisi, 27 (1998).

ÇAYIRDAĞ, Mehmet, Kayseri'de Selçuklu ve Beylikler Dönemine Ait Bazı Kitabe ve Mezar Taşları, Tarih Dergisi, Say1 34, 1984.

ERKİLETLİOĞLU, Halil, Kayseri Tarihi, İl Kültür Müdürlüğü Yayınları, Kayseri 1993.

EDHEM, Halil, Melik Gazi, Anadolu'da İslami Kitabeler, (TOEM), Beşinci Sene, Sayı 32, 1

Haziran 1331.

GÖDE, Kemal, Halil Edhem (Eldem) Kayseri Şehri Selçuklu Tarihinden Bir Bölüm, Kayseri Büyükşsehir Belediyesi Yayınları Kayseri 2011.

GÖKHAN, İlyas, Dulkadir Beyliği, İslam Tarihi ve Medeniyeti, C.11, Siyer Yayınları, İstanbul 2018.

GÖKHAN, İlyas -Rıdvan Yiğit, Sultan Barsbay'ın Diyarbakır Seferi, Kapadokya Tarih ve Sosyal

Bilimler Dergisi, Sayı 1, Aralık 2013.

İBN HACER, İnbâi'l-Gumr bi-Ebnâ'l- Umr, C.8, Darü-1- Kütibi'l- İlmiye, Beyrut 1986.

İBN TAGRIBIIRDİ, Nücumü'z- Zahire,(Çev. Ahsen Batur), Selenge Yayınları, İstanbul 2013.

İBN TAGRİBIRDÎ, Nücumüz-Zahire,(Tahkik:Muhammed Şemseddin Hüseyin) C. 13, Kahire 1992.

MAKRÎZÎ, Kitabü's-Sülük, C.IV/I, II, (Tahk.: Said Abdülfettah Aşur) Matbaatü Darül Kütüp, Kahire 1972.

MEHMED NEŞRİ, Kitâb-ı Cihan- Nümâ, C. I (Yay.: M. A. Köymen, F. R. Unat), TTK Yay., Ankara 1987.

MORDTMANN, J. H, Dulkadırlılar, (Eklemler: M. Halil Yinanç) İA, İstanbul 1977, s.654-662.

ÖZAYDIN, Abdülkerim, Kadı Burhaneddin, DíA, C.24, İstanbul 2001.

ÖZBEK, Yıldıray -Celil Arslan, Kayseri Taşınmaz Varlıklar Envanteri, C. III, Kayseri 2008.

ŞİKARİ, Karamanname (Zamanın kahramanı Karamanîler'in tarihi) Hazr: Metin Sözen, Necdet Sakaoğlu), Karaman Valiliği-Karaman Belediyesi, İstanbul 2005.

UZUNÇARŞILI, İsmail Hakkı, Anadolu Beylikleri, TTK Yay. Ankara 1983.

YINANÇ, Mükrimin Halil, Elbistan, İA, C. 4. Eskişehir 1997.

YINANÇ, Refet, Dulkadir Beyliği, TTK Yayınları Ankara 1989.

YÜCEL, Yaşar, Kadı Burhaneddin Ahmed ve Devleti, Sevinç Matbaası, Ankara 1983.

http://kayseriden.biz/icerik.asp?ICID=209.

http://www.kayseri.gov.tr/diger-camii-ve-medreseler 